\title{
2913. Multi-field coupling dynamic response analysis of pipelines with double corrosion defects under seismic loading in cold regions
}

\author{
Qiao Zhen $\mathrm{Li}^{1}$, Yang $\mathrm{Liu}^{2}$, Li Xin Wei ${ }^{3}$, Min $\mathrm{Luo}^{4}$ \\ ${ }^{1,2,3}$ School of Petroleum Engineering, Northeast Petroleum University, Daqing, China \\ ${ }^{4}$ College of Mechanical Science and Engineering, Northeast Petroleum University, Daqing, China \\ ${ }^{1}$ Corresponding author \\ E-mail: ${ }^{1}$ lqzcxyx@126.com, ${ }^{2} 1658775227 @ q q . c o m,{ }^{3}$ wlxfyx@sina.com, ${ }^{4}$ luomin@nepu.edu.cn
}

Received 21 October 2017; received in revised form 28 December 2017; accepted 5 January 2018 DOI https://doi.org/10.21595/jve.2018.19300

Copyright $(C) 18$ Qiao Zhen Li, et al. This is an open access article distributed under the Creative Commons Attribution License, which permits unrestricted use, distribution, and reproduction in any medium, provided the original work is properly cited.

\begin{abstract}
Multi-field coupling system in the paper is composed of the corroded pipelines, fluid, heat preservation layers and frost -heaving soil, and the buried pipelines are inevitable to be affected by earthquakes, but few studies have been done on corroded pipelines in multi-field coupling under seismic loading in cold regions. The paper analyzes the dynamic response of the pipelines under seismic loading. Method by FEM (finite element method), the three-dimensional multi-field coupling mechanics model has been established for analysis, based on a thermal-fluidsolid multi-field coupling analysis theory, considering the actual stress-strain characteristics of the pipeline steel and the frost heaving force of soil. Meanwhile, the influences of fluid pressure, fluid temperature, corrosion defects and seismic waves on the mechanical properties of the pipelines are then discussed. The results show that: the relative corrosion depth, fluid pressure and fluid temperature have obvious influence on the mechanical properties of corroded pipelines; other factors are relatively weak; the properties of corroded pipelines do not change with different seismic loading. For the corroded pipelines in cold regions, the factors which have obvious influence on the mechanical properties of pipelines should be monitored intensely.
\end{abstract}

Keywords: corroded pipelines, cold regions, seismic loading, multi-field coupling, influence factors.

\section{Introduction}

With the increasing demand for oil and gas resources in China, the pipelines in cold regions have found an increasingly wide utilization, which play a more and more important role in the development of national economy. Due to the particularity of the environment in cold regions, the pipelines not only bear the risks of corrosion, mechanical damage, third-party damage, and so on like the pipelines in ordinary regions, but also the risks of thawing, frost heaving, ice jam, exposed pipelines and others [1-3].

At present, the researches on pipelines in cold regions at home and abroad mainly include the stress, strain, displacement of pipelines [4-7], stability analysis [3, 8], wall thickness selection [9] and so on under the action of frost heaving [2]. The numerical simulation method is currently used to study the stress and displacement [10] and the related influence factors for the pipelines under seismic loading $[11,12]$. The pipelines in cold regions together with the particular environment compose a multi-field coupling system. Once failures of the system occur, they will cause a series of serious consequences [13]. Additionally, earthquakes often happen in China, and the pipelines in cold regions will inevitably face the risk of earthquakes. However, there is little research about the corroded pipelines in cold regions considering the seismic loading and the multi-field coupling effect.

Aiming at the above problems, FEM (finite element method) is used to analyze the dynamic response of the buried corroded pipelines in cold regions considering the multi-field coupling effect, and the mechanical properties of the pipelines changed with fluid temperature, fluid 
pressure, corrosion defects and different seismic waves are then discussed. The results can provide an analytical method and a theoretical basis for the integrity evaluation of pipelines in cold regions.

\section{Physical model}

The length of the pipeline selected is $182.8 \mathrm{~km}$, the specification of the pipeline is $\varnothing 377 \times 6.4 \mathrm{~mm}$, the thickness of heat preservation layer made of rigid polyurethane foam is $40 \mathrm{~mm}$, and the settling depth (from surface to the top of pipeline) is $1.5 \mathrm{~m}$.

The soil itself has a temperature field. From the ground depth $(H)$ and half of the pipeline horizontal radial $(L / 2)$, the pipeline has almost no thermal effect on it. The depth $(H)$ is the constant temperature layer of the soil, and the temperature is $T_{0}^{\prime}$; half of the horizontal radial $(L / 2)$ is considered as adiabatic [14]. Therefore, the object of study can be simplified into a rectangular area according to the thermal effect area, as shown in Fig. 1.

A complex thermal-fluid-solid multi-field coupling model is composed of the corroded pipeline, the fluid in the pipeline, the heat preservation layers and the soil; the fluid-solid coupling model is composed of the corroded pipeline and the fluid in the pipeline; the thermal-solid coupling model is composed of the corroded pipeline, the thermal insulation layer and the soil. The fluid pressure and fluid temperature inside the corroded pipeline are calculated by fluid-solid coupling. The frost heave force and temperature loading outside the corroded pipeline are calculated by thermal-solid coupling. The seismic loading propagation on the pipeline is through the soil.

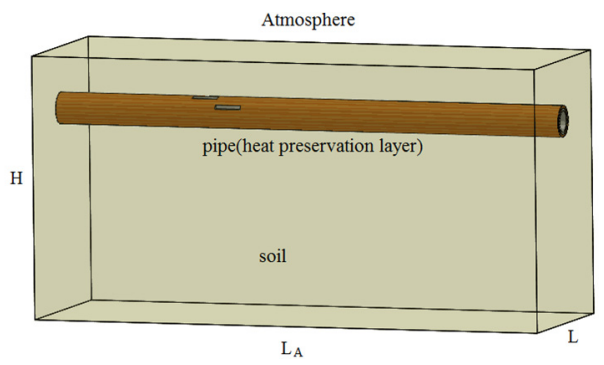

Fig. 1. Three-dimensional physical model

\section{Multi-field coupling mathematical model}

\subsection{Temperature field control equation}

The oil in the long-distance pipeline is continuously dissipating heat from the pipeline, so there is an axial temperature loss. In the paper, corroded pipeline, fluid, heat preservation layer and soil are selected as the research object, and the factors which influence the mechanical properties of pipelines with double corrosion defects are mainly analyzed. Considering that the length of pipe in the research is much shorter compared with the length of long-distance pipelines, so it can be approximately considered that there is no temperature loss in the axial direction. The differential equations $[15,16]$ for heat balance control of temperature field are shown in Eqs. (1-4) respectively.

In the frozen area:

$\rho_{f} C_{f} \frac{\partial T_{f}}{\partial \tau}=\frac{\partial}{\partial x}\left(\lambda_{f} \frac{\partial T_{f}}{\partial x}\right)+\frac{\partial}{\partial y}\left(\lambda_{f} \frac{\partial T_{f}}{\partial y}\right)$.

In the thawing area:

$\rho_{u} C_{u} \frac{\partial T_{u}}{\partial \tau}=\frac{\partial}{\partial x}\left(\lambda_{u} \frac{\partial T_{u}}{\partial x}\right)+\frac{\partial}{\partial y}\left(\lambda_{u} \frac{\partial T_{u}}{\partial y}\right)$. 
Differential equation of unsteady heat conduction for pipeline steel:

$\rho_{1} C_{1} \frac{\partial T_{1}}{\partial \tau}=\lambda_{1}\left(\frac{\partial^{2} T_{1}}{\partial r^{2}}+\frac{1}{r} \frac{\partial T_{1}}{\partial r}+\frac{1}{r^{2}} \frac{\partial^{2} T_{1}}{\partial \theta^{2}}\right)$

Differential equation of unsteady heat conduction for heat preservation layer:

$\rho_{2} C_{2} \frac{\partial T_{2}}{\partial \tau}=\lambda_{2}\left(\frac{\partial^{2} T_{2}}{\partial r^{2}}+\frac{1}{r} \frac{\partial T_{2}}{\partial r}+\frac{1}{r^{2}} \frac{\partial^{2} T_{2}}{\partial \theta^{2}}\right)$

where $\lambda_{f}, \lambda_{u}, \lambda_{1}, \lambda_{2}$ are the thermal conductivity of frozen soil, thawing soil, pipeline and heat preservation layer respectively; $\rho_{f}, \rho_{u}, \rho_{1}, \rho_{2}$ are the density of frozen soil, thawing soil, pipeline and heat preservation layer respectively; $C_{f}, C_{u}, C_{1}, C_{2}$ are the heat capacity of frozen soil, thawing soil, pipeline and heat preservation layer respectively; $T_{f}, T_{u}, T_{1}, T_{2}$ are the temperature of frozen soil, thawing soil, pipeline and heat preservation layer respectively; $\tau$ is time.

\subsection{Multi-field coupling equation}

Under the fluid-solid coupling, the equilibrium differential equation of oil pipeline in cold regions is shown in Eq. (5):

$$
\left\{\begin{array}{l}
\frac{\partial \sigma_{x}^{\prime}}{\partial x}+\frac{\partial \tau_{y x}^{\prime}}{\partial y}+\frac{\partial \tau_{z x}^{\prime}}{\partial z}+f_{x}^{\prime}=0 \\
\frac{\partial \sigma_{y}^{\prime}}{\partial y}+\frac{\partial \tau_{z y}^{\prime}}{\partial z}+\frac{\partial \tau_{x y}^{\prime}}{\partial x}+f_{y}^{\prime}=0 \\
\frac{\partial \sigma_{z}^{\prime}}{\partial z}+\frac{\partial \tau_{x z}^{\prime}}{\partial x}+\frac{\partial \tau_{y z}^{\prime}}{\partial y}+f_{z}^{\prime}=0
\end{array}\right.
$$

Here: $\sigma_{i j}^{\prime}$ is the pipeline stress under fluid - solid coupling; $f_{i}^{\prime}$ is the force acting on the corroded pipeline.

Under thermal-solid coupling, the subsidiary thermal stress and thermal strain will come after the temperature variation. Therefore, assuming that the initial temperature of the pipeline is $T_{g 0}$, when the temperature increases to $T_{g 2}$ (the temperature is related to the temperature field control equation), the pipeline will expand, resulting in thermal strain $\varepsilon^{\prime}=-\beta\left(T_{g 2}-T_{g 0}\right) . \beta$ is the linear expansion coefficient of the pipeline.

Therefore, the total deformation component of the pipeline is [17]:

$$
\left\{\begin{array}{l}
\varepsilon_{x}=\frac{1}{E}\left[\sigma_{x}^{\prime}-\mu\left(\sigma_{y}^{\prime}+\sigma_{z}^{\prime}\right)\right]+\beta\left(T_{g 2}-T_{g 0}\right), \\
\varepsilon_{y}=\frac{1}{E}\left[\sigma_{y}^{\prime}-\mu\left(\sigma_{z}^{\prime}+\sigma_{x}^{\prime}\right)\right]+\beta\left(T_{g 2}-T_{g 0}\right), \\
\varepsilon_{z}=\frac{1}{E}\left[\sigma_{z}^{\prime}-\mu\left(\sigma_{x}^{\prime}+\sigma_{y}^{\prime}\right)\right]+\beta\left(T_{g 2}-T_{g 0}\right), \\
\gamma_{x y}=\frac{\tau_{x y}^{\prime}}{G} \\
\gamma_{y z}=\frac{\tau_{y z}^{\prime}}{G} \\
\gamma_{z x}=\frac{\tau_{z x}^{\prime}}{G} .
\end{array}\right.
$$


The first three terms of Eq. (6) are added, and then the Eq. (7) is obtained:

$\sigma_{x}^{\prime}+\sigma_{y}^{\prime}+\sigma_{z}^{\prime}=\frac{E}{2 \mu}\left[\left(\varepsilon_{x}+\varepsilon_{y}+\varepsilon_{z}\right)-3 \beta\left(T_{g 2}-T_{g 0}\right)\right]$

The stress of the pipeline is obtained by substituting Eq. (7) into the first three terms of Eq. (6):

$$
\left\{\begin{array}{l}
\sigma_{x}^{\prime}=\frac{E}{1+\mu} \varepsilon_{x}+\frac{E \mu}{(1+\mu)(1-2 \mu)}\left(\varepsilon_{x}+\varepsilon_{y}+\varepsilon_{z}\right)-\frac{E}{1-2 \mu} \beta\left(T_{g 2}-T_{g 0}\right) \\
\sigma_{y}^{\prime}=\frac{E}{1+\mu} \varepsilon_{y}+\frac{E \mu}{(1+\mu)(1-2 \mu)}\left(\varepsilon_{x}+\varepsilon_{y}+\varepsilon_{z}\right)-\frac{E}{1-2 \mu} \beta\left(T_{g 2}-T_{g 0}\right) \\
\sigma_{z}^{\prime}=\frac{E}{1+\mu} \varepsilon_{z}+\frac{E \mu}{(1+\mu)(1-2 \mu)}\left(\varepsilon_{x}+\varepsilon_{y}+\varepsilon_{z}\right)-\frac{E}{1-2 \mu} \beta\left(T_{g 2}-T_{g 0}\right) \\
\tau_{x y}^{\prime}=\frac{E}{2(1+\mu)} \gamma_{x y}, \\
\tau_{y z}^{\prime}=\frac{E}{2(1+\mu)} \gamma_{y z}, \\
\tau_{z x}^{\prime}=\frac{E}{2(1+\mu)} \gamma_{z x} .
\end{array}\right.
$$

The Eq. (9) is obtained by substituting the Lemma coefficient, shear modulus and bulk modulus formula into Eq. (8) respectively:

$$
\left\{\begin{array}{l}
\sigma_{x}^{\prime}=2 G \varepsilon_{x}+\lambda\left(\varepsilon_{x}+\varepsilon_{y}+\varepsilon_{z}\right)-3 K \beta\left(T_{g 2}-T_{g 0}\right), \\
\sigma_{y}^{\prime}=2 G \varepsilon_{y}+\lambda\left(\varepsilon_{x}+\varepsilon_{y}+\varepsilon_{z}\right)-3 K \beta\left(T_{g 2}-T_{g 0}\right), \\
\sigma_{z}^{\prime}=2 G \varepsilon_{z}+\lambda\left(\varepsilon_{x}+\varepsilon_{y}+\varepsilon_{z}\right)-3 K \beta\left(T_{g 2}-T_{g 0}\right), \\
\tau_{x y}^{\prime}=G \gamma_{x y} \\
\tau_{y z}^{\prime}=G \gamma_{y z} \\
\tau_{z x}^{\prime}=G \gamma_{z x} .
\end{array}\right.
$$

In the space problem, the deformation component and the displacement component should satisfy six geometric equations:

$$
\left\{\begin{array}{l}
\varepsilon_{x}=\frac{\partial u^{\prime}}{\partial x} \\
\varepsilon_{y}=\frac{\partial v^{\prime}}{\partial x} \\
\varepsilon_{z}=\frac{\partial w^{\prime}}{\partial x} \\
\gamma_{y z}=\frac{\partial w^{\prime}}{\partial y}+\frac{\partial v^{\prime}}{\partial z} \\
\gamma_{z x}=\frac{\partial u^{\prime}}{\partial z}+\frac{\partial w^{\prime}}{\partial x} \\
\gamma_{x y}=\frac{\partial v^{\prime}}{\partial x}+\frac{\partial u^{\prime}}{\partial y}
\end{array}\right.
$$

The Eq. (9) is substituted into Eq. (5), and the spatial geometric relations equation Eq. (10) is used to obtain the coupling deformation equation of the pipeline: 


$$
\left\{\begin{array}{l}
(2 G+\lambda) \frac{\partial^{2} u^{\prime}}{\partial x^{2}}+(G+\lambda) \frac{\partial^{2} v^{\prime}}{\partial x \partial y}+(G+\lambda) \frac{\partial^{2} w^{\prime}}{\partial x \partial z}+G \frac{\partial^{2} u^{\prime}}{\partial y^{2}}+G \frac{\partial^{2} u^{\prime}}{\partial z^{2}}-3 K \beta \frac{\partial T_{g 2}}{\partial x}+f_{x}^{\prime}=0, \\
(2 G+\lambda) \frac{\partial^{2} v^{\prime}}{\partial y^{2}}+(G+\lambda) \frac{\partial^{2} u^{\prime}}{\partial y \partial x}+(G+\lambda) \frac{\partial^{2} w^{\prime}}{\partial y \partial z}+G \frac{\partial^{2} v^{\prime}}{\partial z^{2}}+G \frac{\partial^{2} v^{\prime}}{\partial x^{2}}-3 K \beta \frac{\partial T_{g 2}}{\partial y}+f_{y}^{\prime}=0, \\
(2 G+\lambda) \frac{\partial^{2} w^{\prime}}{\partial z^{2}}+(G+\lambda) \frac{\partial^{2} u^{\prime}}{\partial x \partial z}+(G+\lambda) \frac{\partial^{2} v^{\prime}}{\partial y \partial z}+G \frac{\partial^{2} w^{\prime}}{\partial x^{2}}+G \frac{\partial^{2} w^{\prime}}{\partial y^{2}}-3 K \beta \frac{\partial T_{g 2}}{\partial z}+f_{z}^{\prime}=0 .
\end{array}\right.
$$

In the equations, $u^{\prime}, v^{\prime}, w^{\prime}$ are the displacement component produced by the internal pressure, the temperature difference and the soil force of the corroded pipeline respectively, and $f_{x}^{\prime}, f_{y}^{\prime}, f_{z}^{\prime}$ are the component of the force acting on the corroded pipeline respectively.

Eq. (11) is the multi field coupling deformation equation of the pipeline, which contains the coupling term reflecting the change of temperature field. Therefore, the temperature field equation should be considered to get the solution of Eq. (11).

\section{Finite element model}

\subsection{Basic data}

Two corrosion defects of the pipeline are located close to interact each other and the characteristic parameters are shown in Table 1. Fig. 2 shows geometric dimensions of the individual defects. The corrosion defect 1 is located at Pipeline 00:00 position; the corrosion defect 2 and the corrosion defect 1 have the circumferential distance of 30 degrees, and the two defects have no axial spacing.

For the convenience of numerical simulation, the irregular corrosion defects are simplified into rectangular areas, and the size of the rectangular area is determined by the maximum defect depth and the maximum defect length.

For the pipeline, the actual stress-strain curve is used, and the curve is calculated by the constitutive model of Ramberg-Osgood [18].

Table 1. Parameters for double corrosion defects

\begin{tabular}{|l|c|c|c|}
\hline & $\begin{array}{c}\text { The relative corrosion } \\
\text { depth }(d / t)\end{array}$ & $\begin{array}{c}\text { The relative corrosion } \\
\text { length }(L / \sqrt{D t})\end{array}$ & $\begin{array}{c}\text { The relative corrosion } \\
\text { width }\left(\theta / 180^{\circ}\right)\end{array}$ \\
\hline Corrosion defect 1 & 0.4 & 2.9 & 0.1 \\
\hline Corrosion defect 2 & 0.4 & 2.9 & 0.1 \\
\hline $\begin{array}{l}\text { Notes: } d \text { is the measured maximum corrosion pit depth of the corrosion defect, } t \text { is the wall thickness of } \\
\text { pipeline; } L \text { is the allowable maximum longitudinal length; } D \text { is the pipe OD; } \theta \text { is the angle of corrosion } \\
\text { defects along the pipeline }\end{array}$ \\
\hline
\end{tabular}

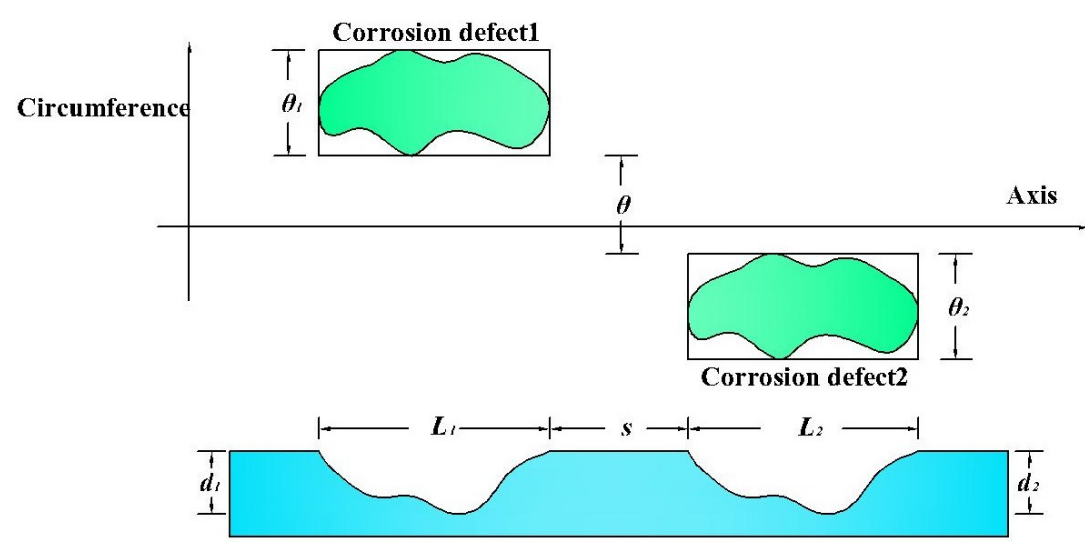

Fig. 2. Geometric dimensions of the individual defects 
Other basic parameters [19] of pipeline steel are shown in Table 2. Data of heat preservation layer and soil refer to data in the references [20,21].

Table 2. Basic parameters of pipeline steel

\begin{tabular}{|c|c|c|c|}
\hline $\begin{array}{c}\text { Density / } \\
\mathrm{kg} \cdot \mathrm{m}^{-3}\end{array}$ & $\begin{array}{c}\text { Linear expansion coefficient / } \\
\mathrm{mm} \cdot\left(\mathrm{mm} \cdot{ }^{\circ} \mathrm{C}\right)^{-1}\end{array}$ & $\begin{array}{c}\text { Thermal conductivity / } \\
\mathrm{W} \cdot\left(\mathrm{m} \cdot{ }^{\circ} \mathrm{C}\right)^{-1}\end{array}$ & $\begin{array}{c}\text { Specific heat capacity / } \\
\mathrm{J} \cdot\left(\mathrm{kg} \cdot{ }^{\circ} \mathrm{C}\right)^{-1}\end{array}$ \\
\hline 7833 & $1.112 \times 10^{-5}\left(20^{\circ} \sim 50^{\circ}\right)$ & 46 & 750 \\
\hline
\end{tabular}

\subsection{Boundary conditions}

Because the research object is long-distance transportation pipeline, it can be approximately considered that there is no axial displacement in the pipeline. An axial displacement constraint is imposed on one end of the pipeline and the other end is imposed on its symmetric displacement constraints.

On the basis of the above analysis, a three-dimensional thermal-fluid-solid multi-field coupling mechanical model is established, composed of double corroded pipelines, heat preservation layers and soil, the load boundary conditions and displacement boundary conditions are applied to the model.

Load boundary conditions: the internal fluid pressure is $4 \mathrm{MPa}$, the temperature is $48{ }^{\circ} \mathrm{C}$, and the average velocity is $0.75 \mathrm{~m} / \mathrm{s}$. The external atmospheric temperature is $19.4{ }^{\circ} \mathrm{C}$, the air convection coefficient is $12.5 \mathrm{w} /\left(\mathrm{m}^{2} \cdot \mathrm{k}\right)$, and a constant temperature load of $4{ }^{\circ} \mathrm{C}$ is applied on the bottom of the constant temperature layer. The pipeline is subjected to the action of EL-centro seismic loading [22], and the action time of seismic loading is $30 \mathrm{~s}$; the direction of the wave action is along the axial direction of pipeline [23], and the curve of acceleration time is shown in Fig. 3.

Displacement boundary conditions: the displacement at the bottom of the simplified rectangular region (constant temperature layer) is completely restrained; the displacement of the connection between the soil's surface and atmospheric is free; an axial displacement constraint is applied at one end of the cross section of the pipeline, and a symmetric displacement constraint is applied at the other end; the symmetrical displacement constraints are applied to the axial section of pipeline; the displacement constraint is applied on the other side of the rectangular region.

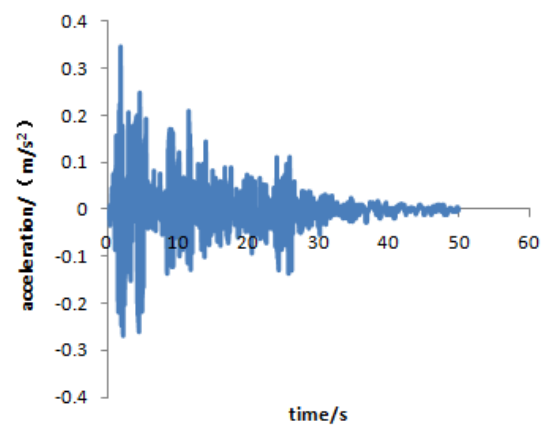

Fig. 3. Curve for acceleration time of EL-centro seismic loading

\subsection{Mesh model}

The structure of pipeline, fluid, heat preservation layer and soil are discretized respectively, and then the whole mesh model is shown in Fig. 4.

\section{Analysis of influence factors}

In order to study the mechanical properties of corroded pipelines with multi-field coupling 
effect under seismic loading, the numerical simulation of different fluid temperature, different fluid pressure, different defect characteristics and different types of seismic loading are developed, and the results are analyzed and discussed.

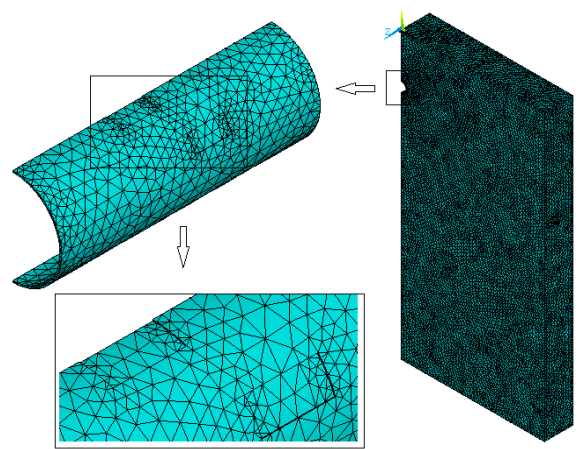

a) Mesh model of solid with double corrosion defects

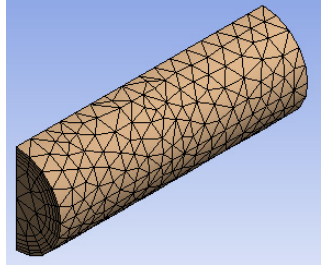

b) Mesh model of pipeline fluid

Fig. 4. The overall three-dimensional mesh model

\subsection{Influence of fluid temperature in pipeline}

In the premise of other load boundary conditions and displacement boundary conditions invariant, multi-field couplings numerical simulation for pipelines with double corrosion defects with fluid temperatures of $40{ }^{\circ} \mathrm{C}, 48{ }^{\circ} \mathrm{C}, 53{ }^{\circ} \mathrm{C}$ and $60{ }^{\circ} \mathrm{C}$ are carried out respectively. Curves for the stress, displacement and strain of the corroded pipeline, changed with fluid temperature, are shown in Figs. 5-7 respectively. The maximum strain distribution of the corroded pipeline is shown in Fig. 8.

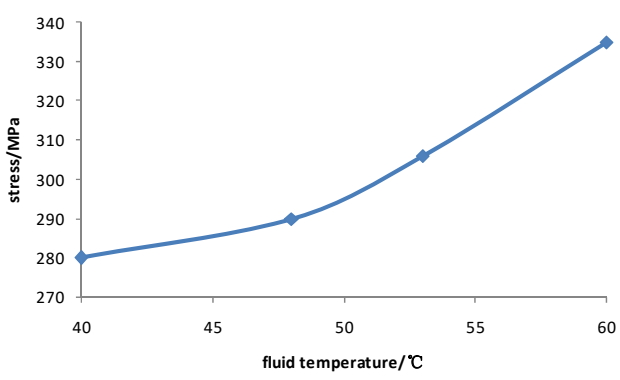

Fig. 5. Curve for stress of corroded pipeline changed with fluid temperature

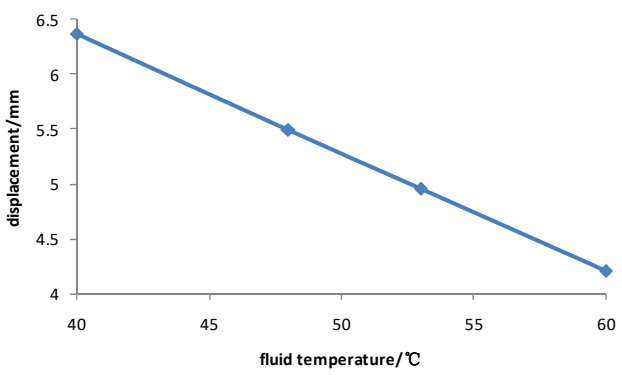

Fig. 6. Curve for displacement of corroded pipeline changed with fluid temperature

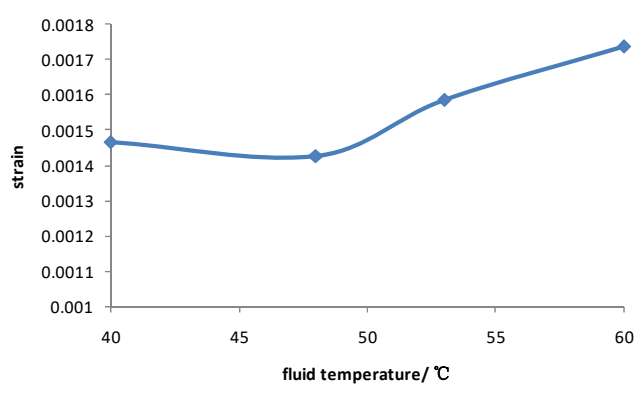

Fig. 7. Curve for strain of corroded pipeline changed with fluid temperature

Fig. 5 shows that the pipeline stress increases with the increasing of the fluid temperature. The value of stress is $280 \mathrm{MPa}$ when the fluid temperature is $40{ }^{\circ} \mathrm{C}$, while the value of stress is 
$335 \mathrm{MPa}$ when the fluid temperature is $60^{\circ} \mathrm{C}$, with an increase of $19.6 \%$.

Fig. 6 shows that with the increase of the fluid temperature, the maximum displacement of the pipeline shows a downward trend. The value of displacement is $6 \mathrm{~mm}$ when the fluid temperature is $40{ }^{\circ} \mathrm{C}$, and drops to $4 \mathrm{~mm}$ when the fluid temperature is $60{ }^{\circ} \mathrm{C}$, with a decrease of $33.3 \%$.

Fig. 7 and Fig. 8 shows that with the increase of fluid temperature, the strain of pipeline presents a steady change and then increases obviously. When the fluid temperature at the top corrosion of pipeline is $40{ }^{\circ} \mathrm{C}$, the maximum strain with the value of 0.0015 ; when the fluid temperature exceeds $48^{\circ} \mathrm{C}$, the maximum strain increases continuously, but the position does not change, and it appears in the corrosion pits near the middle of pipeline. The fluid temperature increases by $50 \%$, and the strain of the pipeline with double corrosion defects increases by $18.5 \%$.

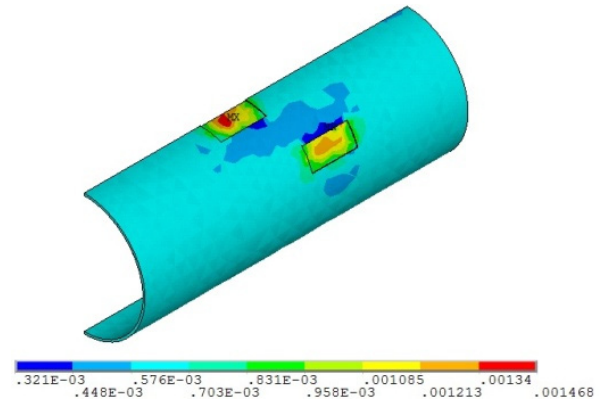

a) Fluid temperature is $40^{\circ} \mathrm{C}$

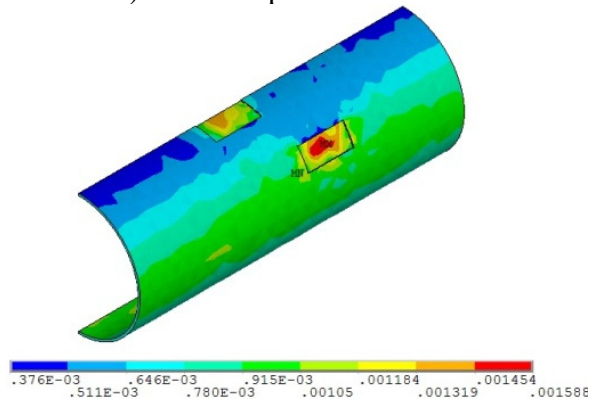

c) Fluid temperature is $53{ }^{\circ} \mathrm{C}$

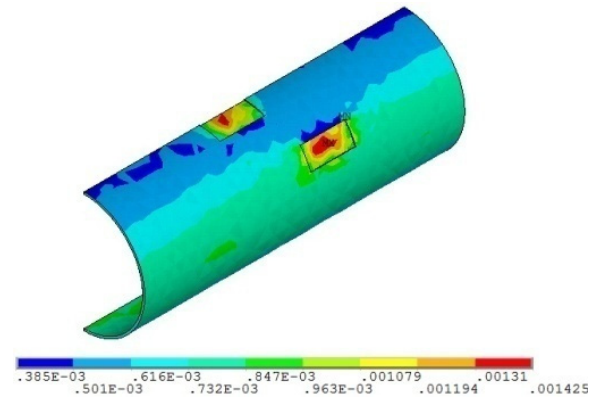

b) Fluid temperature is $48^{\circ} \mathrm{C}$

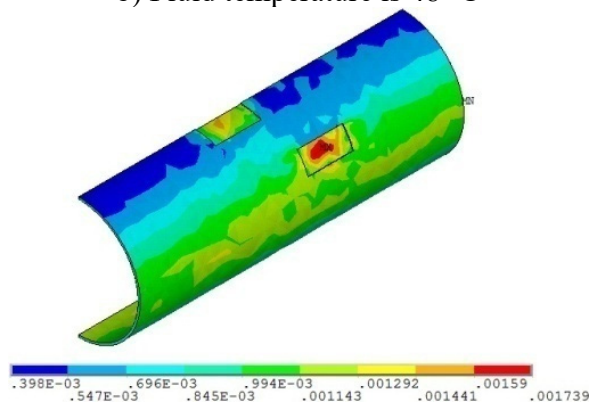

d) Fluid temperature is $60^{\circ} \mathrm{C}$

Fig. 8. Distribution position for maximum strain of corroded pipeline with different fluid temperature

\subsection{Influence of fluid pressure in pipeline}

In the premise of other load boundary conditions and displacement boundary conditions invariant, multi-field couplings numerical simulation for the pipelines with double corrosion defects with fluid pressure of $4 \mathrm{MPa}, 5 \mathrm{MPa}, 6 \mathrm{MPa}$ and $10 \mathrm{MPa}$ are carried out respectively. Curves for stress, displacement and strain of the corroded pipeline changed with fluid pressure are shown in Figs. 9-11 respectively. The maximum strain distribution of the corroded pipelines is shown in Fig. 12.

Fig. 9 shows that the pipeline stress increases with the increasing of fluid pressure. The value of stress is $290 \mathrm{MPa}$ when the fluid pressure is $4 \mathrm{MPa}$, while the value of stress is $597 \mathrm{MPa}$ when the fluid pressure is $10 \mathrm{MPa}$, with an increase of 1.1 times.

Fig. 10 shows that the total displacement of the pipeline is approximately not changed with the increasing of fluid pressure, and the maximum value is about $5 \mathrm{~mm}$ all the time.

Fig. 11 and Fig. 12 shows that the strain of double corroded pipeline increases with the increasing of fluid pressure, but the position of maximum strain remains unchanged, which is located in the corrosion pit near the middle of pipeline. When the fluid pressure is $4 \mathrm{MPa}$, the maximum value of double corroded pipeline strain is 0.0014 ; when the fluid pressure increases to 
$10 \mathrm{MPa}$, the maximum value of double corroded pipeline strain is 0.0029 .

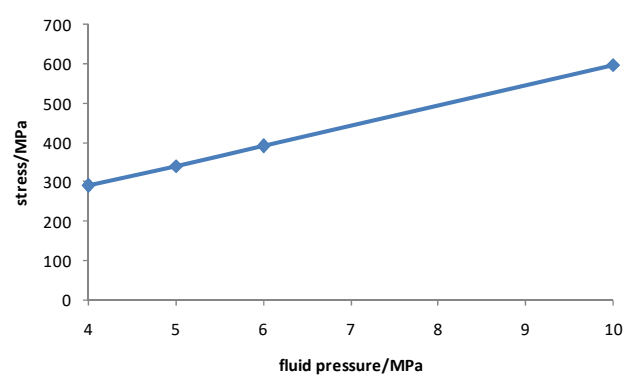

Fig. 9. Curve for stress of corroded pipeline changed with fluid pressure

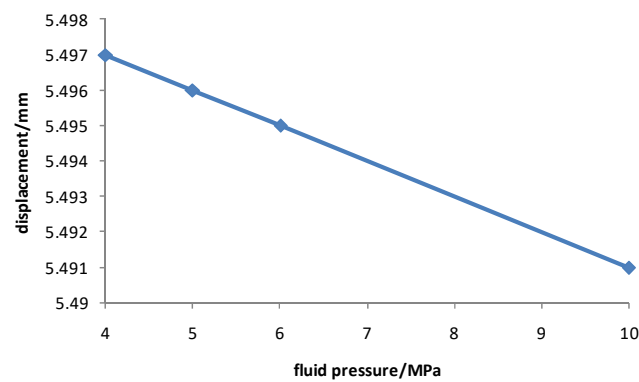

Fig. 10. Curve for displacement of corroded pipeline changed with fluid pressure

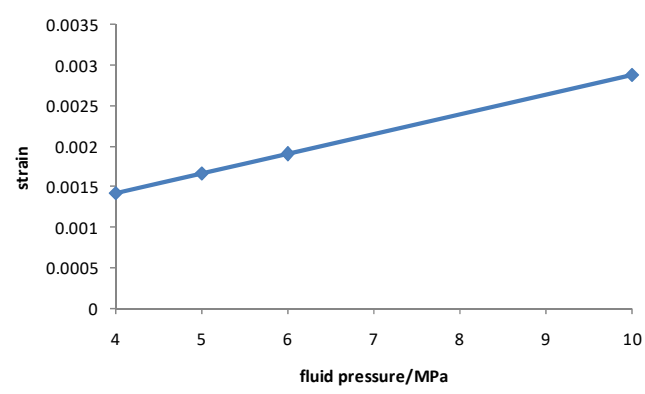

Fig. 11. Curve for strain of corroded pipeline changed with fluid pressure

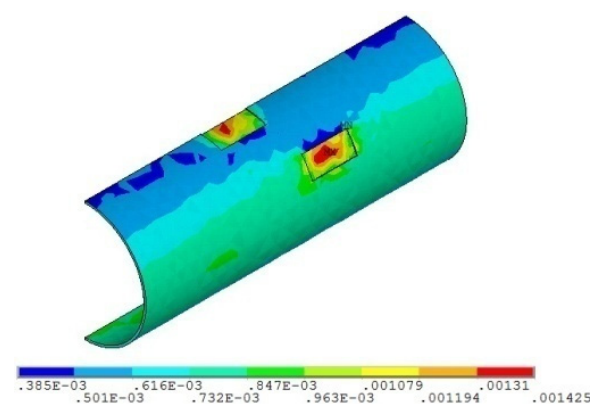

a) Fluid pressure is $4 \mathrm{MPa}$

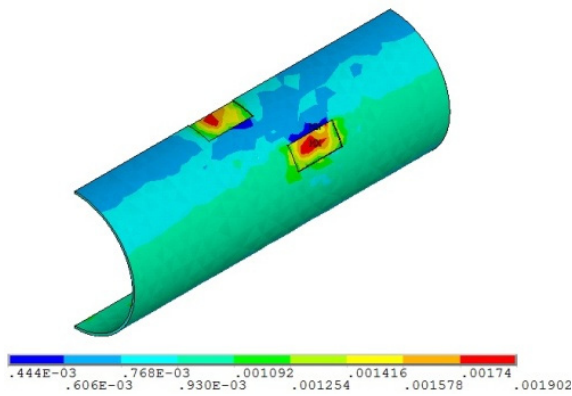

c) Fluid pressure is $6 \mathrm{MPa}$

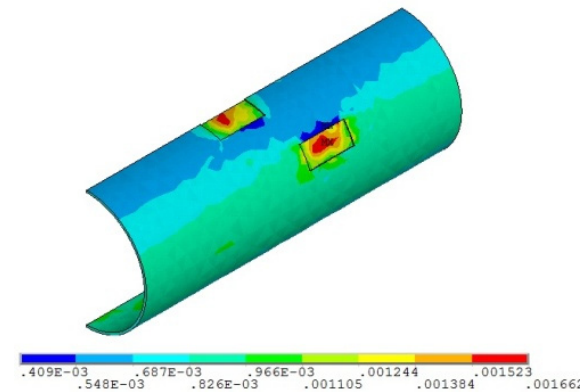

b) Fluid pressure is $5 \mathrm{MPa}$

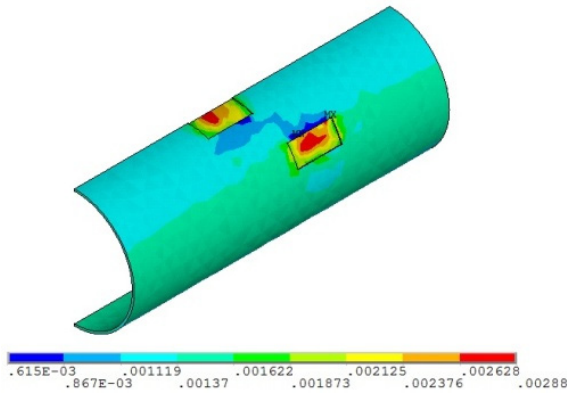

d) Fluid pressure is $10 \mathrm{MPa}$

Fig. 12. Distribution position for maximum strain of corroded pipeline with different fluid pressure

\subsection{Influence of corrosion defects characteristics}

In the premise of other load boundary conditions and displacement boundary conditions 
invariant, multi-field couplings numerical simulation for the pipelines with double corrosion defects with different relative corrosion depths, different relative corrosion lengths and different relative corrosion widths under seismic loading are carried out respectively. The calculation conditions are shown in Table 3.

Table 3. Calculation conditions of different defect characteristics considering the earthquake time history effect

\begin{tabular}{|c|c|c|}
\hline $\begin{array}{c}\text { Case } \\
\text { number }\end{array}$ & Case name & Concrete content \\
\hline 1 & $\begin{array}{c}\text { Influence of } \\
\text { relative corrosion } \\
\text { depth }\end{array}$ & $\begin{array}{c}\text { When the other characteristic parameters of the defect are invariant, the } \\
\text { multi-field coupling analysis is carried out on the corroded pipeline } \\
\text { with the relative corrosion depth of } 0.3,0.4,0.5 \text { and } 0.6 \text { respectively. }\end{array}$ \\
\hline 2 & $\begin{array}{c}\text { Influence of } \\
\text { relative corrosion } \\
\text { length }\end{array}$ & $\begin{array}{c}\text { When the other characteristic parameters of the defect are invariant, the } \\
\text { multi-field coupling analysis is carried out on the corroded pipeline } \\
\text { with the relative corrosion length of 2.9, 6.2 and 8.2 respectively. }\end{array}$ \\
\hline 3 & $\begin{array}{c}\text { Influence of } \\
\text { relative corrosion } \\
\text { width }\end{array}$ & $\begin{array}{c}\text { When the other characteristic parameters of the defect are invariant, the } \\
\text { multi-field coupling analysis is carried out on the corroded pipeline } \\
\text { with the relative corrosion width of } 0.1,0.3 \text { and 0.4 respectively. }\end{array}$ \\
\hline
\end{tabular}

\subsubsection{Influence of relative corrosion depth}

According to the multi-field coupling analysis, curves for stress, displacement and strain of pipelines with double corrosion defects changed with the relative corrosion depth under seismic loading are drawn, as shown in Figs. 13-15 respectively. The maximum strain distribution of corroded pipelines is shown in Fig. 16.

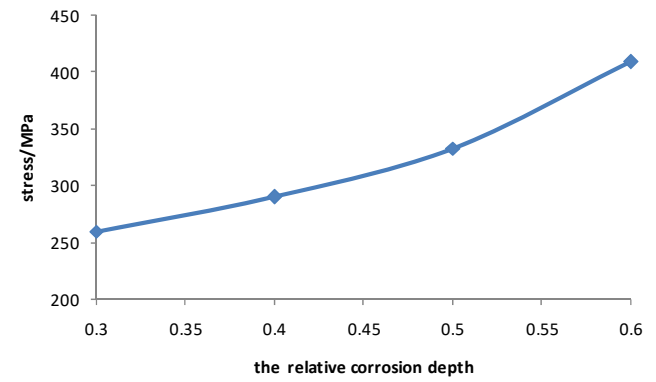

Fig. 13. Curve for stress of corroded pipeline changed with relative corrosion depth

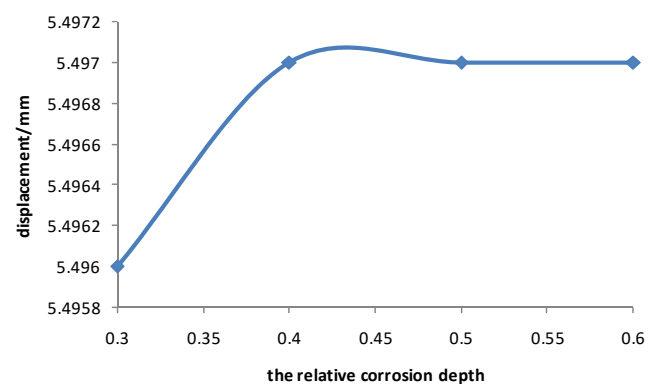

Fig. 14. Curve for displacement of corroded pipeline changed with relative corrosion depth

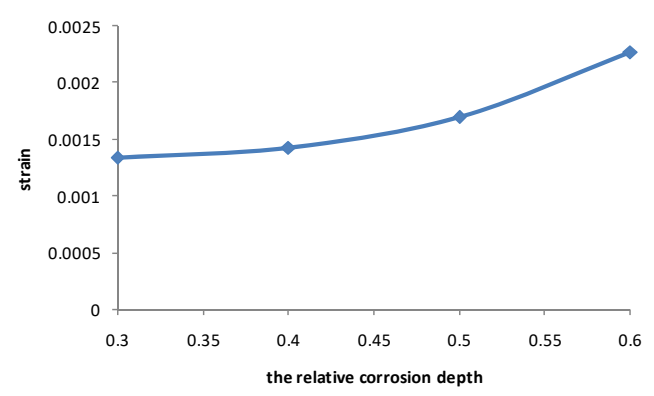

Fig. 15. Curve for strain of the pipeline with double corrosion defects changed with the relative corrosion depth

Fig. 13 shows that the pipeline stress increases with the increasing of the relative corrosion depth. The value of stress is $290 \mathrm{MPa}$ when the relative corrosion depth is 0.3 , while the value of stress is $409 \mathrm{MPa}$ when the relative corrosion depth is 0.6 , with an increase of $57.3 \%$. 
Fig. 14 shows that the total displacement of pipeline is approximately not changed with the increasing of the relative corrosion depth, and the maximum value is always about $5.5 \mathrm{~mm}$.

Fig. 15 and Fig. 16 show that the strain of the pipeline with double corrosion defects increases with the increasing of the relative corrosion depth, but the maximum position remains unchanged, which is located in the corrosion pit near the middle of pipeline. When the relative corrosion depth is 0.3 , the maximum value of the pipeline with double corrosion defects is 0.0013 ; when the relative corrosion depth is 0.6 , the maximum value of the corroded pipeline strain is 0.0023 .

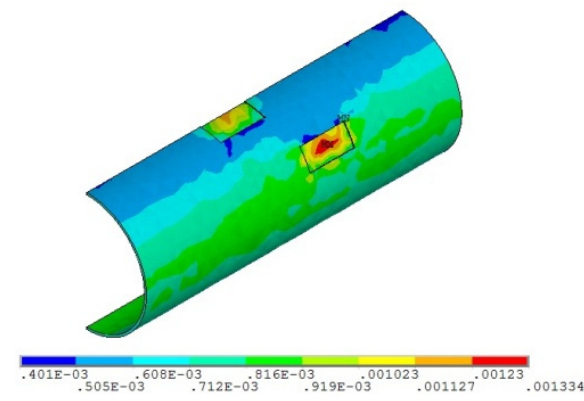

a) Relative corrosion depth is 0.3

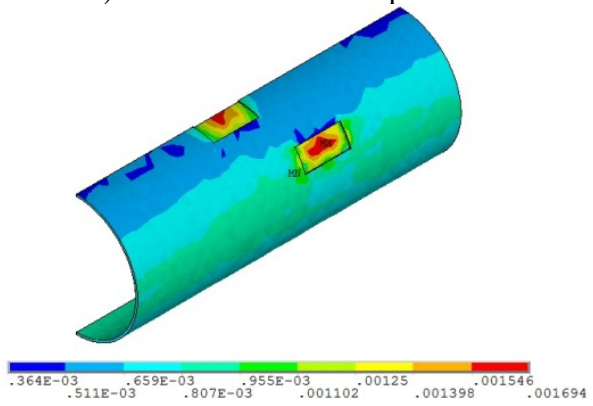

c) Relative corrosion depth is 0.5

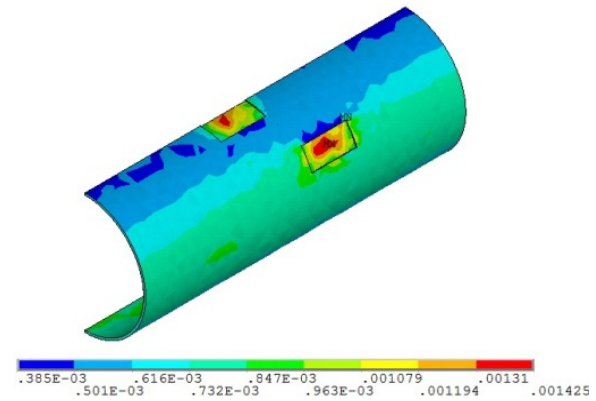

b) Relative corrosion depth is 0.4

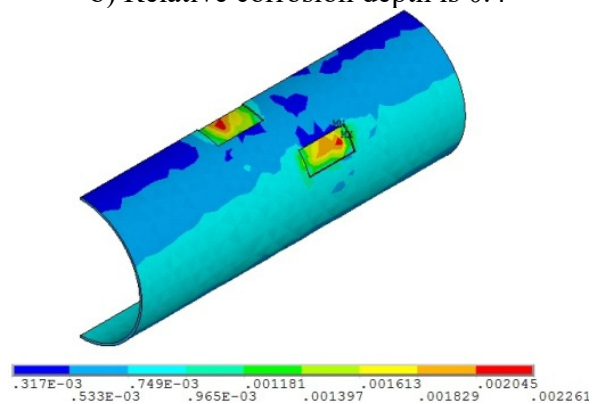

d) Relative corrosion depth is 0.6

Fig. 16. Distribution position for maximum strain of the pipeline with double corrosion defects with different relative corrosion depth

\subsubsection{Influence of relative corrosion length}

According to the multi-field coupling analysis, curves for stress, displacement and strain of the pipeline with double corrosion defects changed with the relative corrosion length under seismic loading are drawn, as shown in Figs. 17-19 respectively. The maximum strain distribution of the corroded pipeline is shown in Fig. 20.

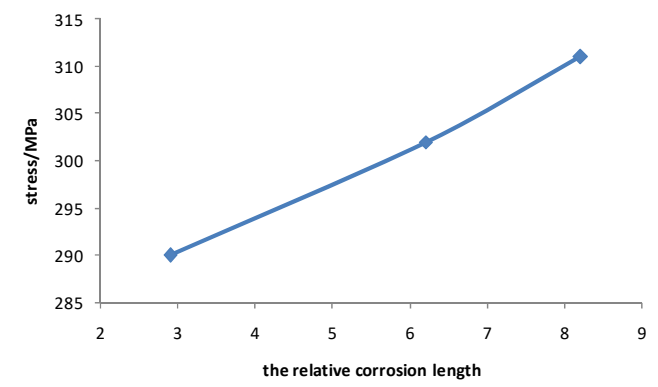

Fig. 17. Curve for stress of corroded pipeline changed with relative corrosion length

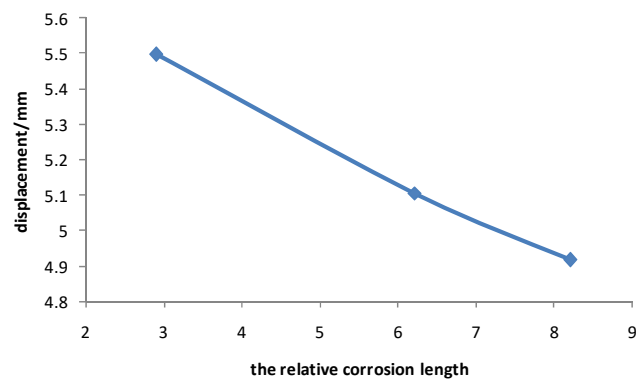

Fig. 18. Curve for displacement of corroded pipeline changed with relative corrosion length

Fig. 17 shows that the pipeline stress increases with the increasing of the relative corrosion 
length. The value of stress is $290 \mathrm{MPa}$ when the relative corrosion length is 2.9 , while the value of stress is $311 \mathrm{MPa}$ when the relative corrosion length is 8.2 , with an increase of $7.2 \%$.

Fig. 18 shows that the maximum displacement of the pipeline with double corrosion defects decreases slightly with the increase of the relative corrosion length, and it can be approximately considered that the displacement does not change with the increase of the relative corrosion length.

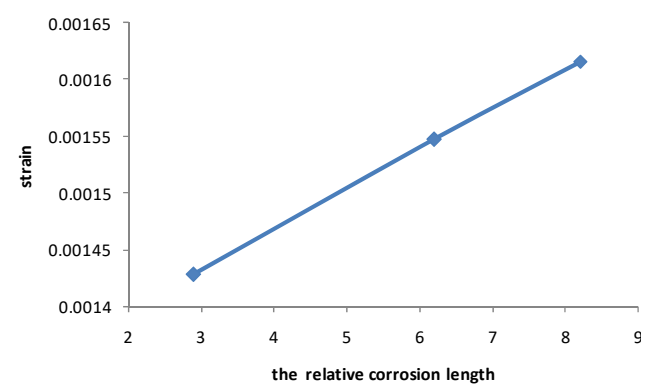

Fig. 19. Curve for strain of the pipeline with double corrosion defects changed with the relative corrosion length

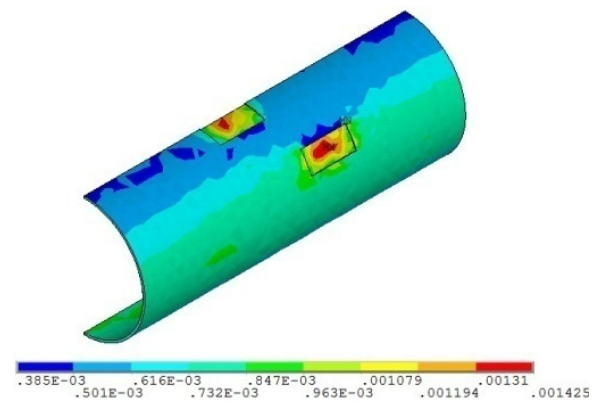

a) Relative corrosion length is 2.9

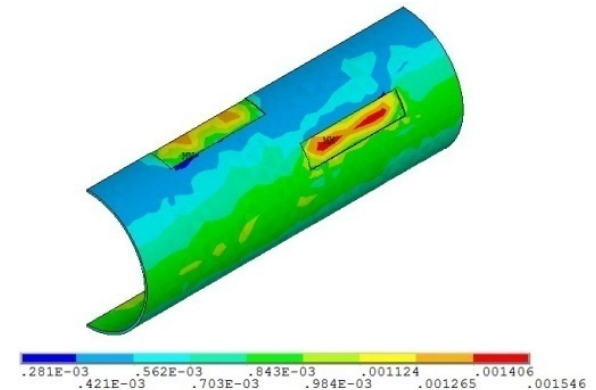

b) Relative corrosion length is 6.2

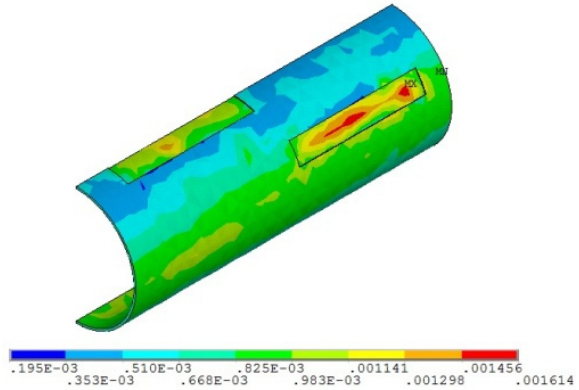

c) Relative corrosion length is 8.2

Fig. 20. Distribution position for maximum strain of the corroded pipeline with different relative corrosion lengths

Fig. 19 and Fig. 20 show that the strain of the pipeline with double corrosion defects increases with the increasing of the relative corrosion length, but the maximum position remains invariant, which is located in the corrosion pit near the middle of pipeline. When the relative corrosion length is 2.9, the maximum value of the strain of the pipeline with double corrosion defects is 0.0014 ; when the relative corrosion length is 8.2 , the maximum value of the corroded pipeline strain is 0.0016 .

\subsubsection{Influence of relative corrosion width}

According to the multi-field coupling analysis, curves for stress, displacement and strain of 
the pipeline with double corrosion defects changed with the relative corrosion width under seismic loading are drawn, as shown in Figs. 21-23 respectively. The maximum strain distribution of the corroded pipeline is shown in Fig. 24.

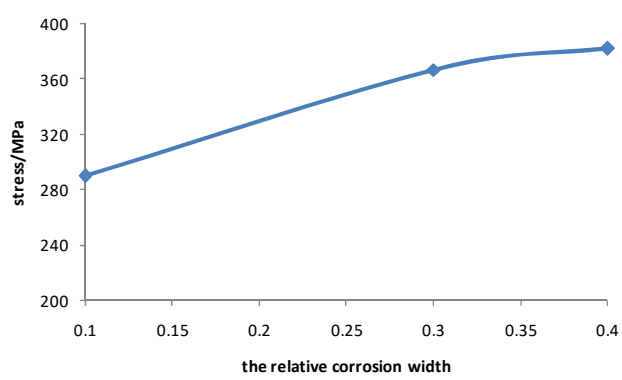

Fig. 21. Curve for stress of corroded pipeline changed with relative corrosion width

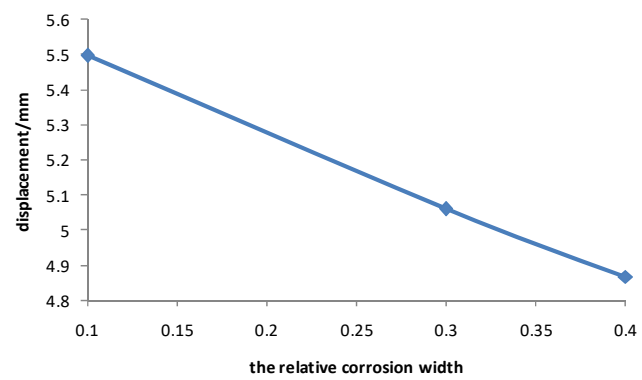

Fig. 22. Curve for displacement of corroded pipeline Changed with relative corrosion width

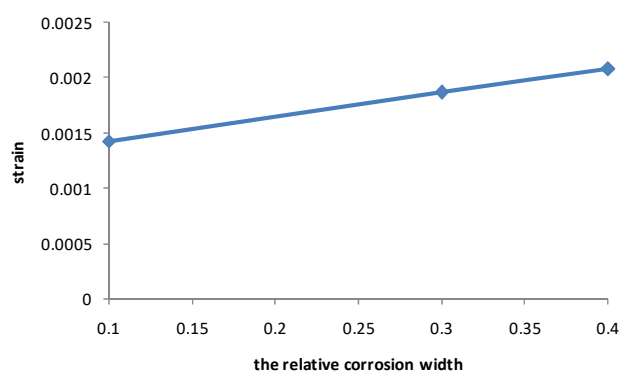

Fig. 23. Curve for strain of the corroded pipeline changed with the relative corrosion width

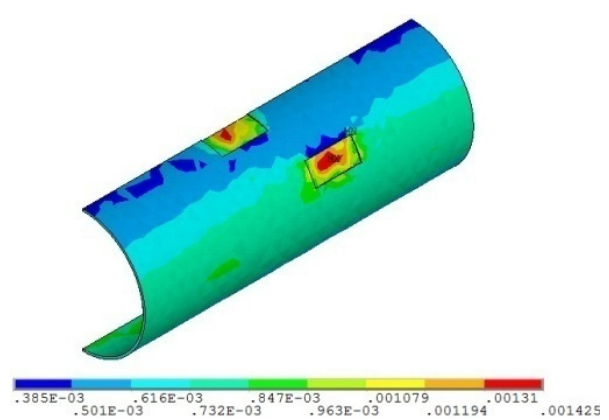

a) Relative corrosion width is 0.1

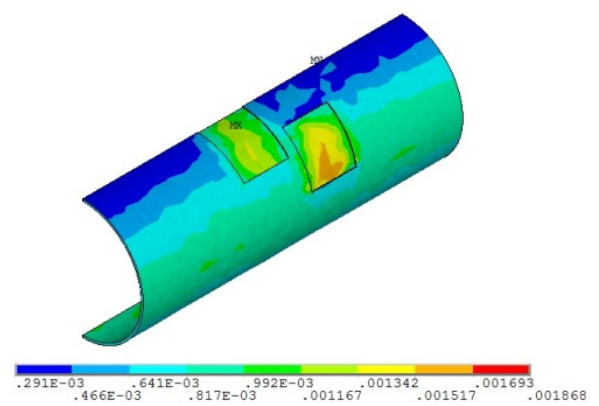

b) Relative corrosion width is 0.3

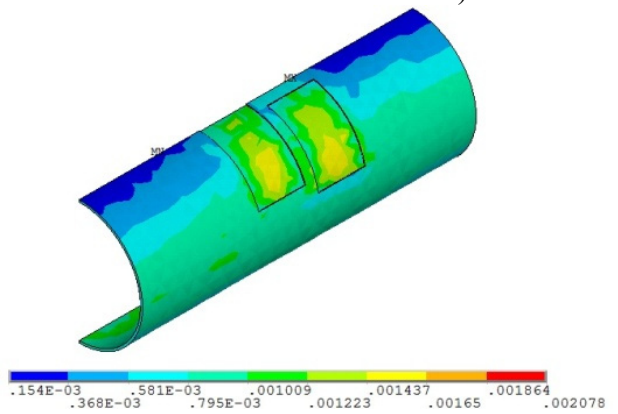

c) Relative corrosion width is 0.4

Fig. 24. Distribution position for maximum strain of the pipeline with double corrosion defects with different relative corrosion widths 
Fig. 21 shows that the pipeline stress increases with the increasing of the relative corrosion width. The value of stress is $290 \mathrm{MPa}$ when the relative corrosion width is 0.1 , while value of stress is $382 \mathrm{MPa}$ when the relative corrosion width is 0.4 , with an increase of $31.7 \%$.

It can be seen from Fig. 22 that the maximum displacement of the pipeline with double corrosion defects decreases slightly with the increase of the relative corrosion width, and it can be approximately considered that the displacement does not change with the increase of the relative corrosion width.

Fig. 23 and Fig. 24 show that the strain of the pipeline with double corrosion defects increases with the increasing of the relative corrosion length, and the maximum position changes. When the relative corrosion width is 0.1 , the maximum value is 0.0014 , located in the corrosion pit near the middle of pipeline; when the relative width is up to 0.4 , the maximum value is 0.0021 , located on the top of pipeline. Thus, the wider the relative corrosion width is, the defects at the top of pipeline are more likely to fail.

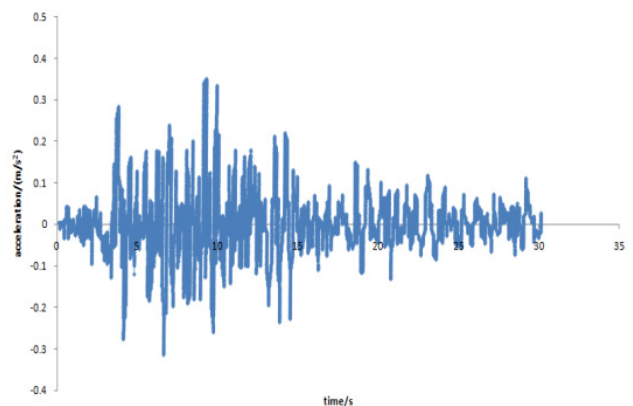

Fig. 25. Curve for acceleration time-history of Taft seismic loading

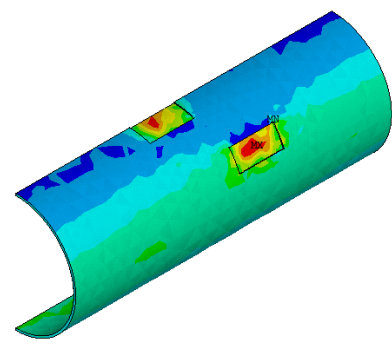

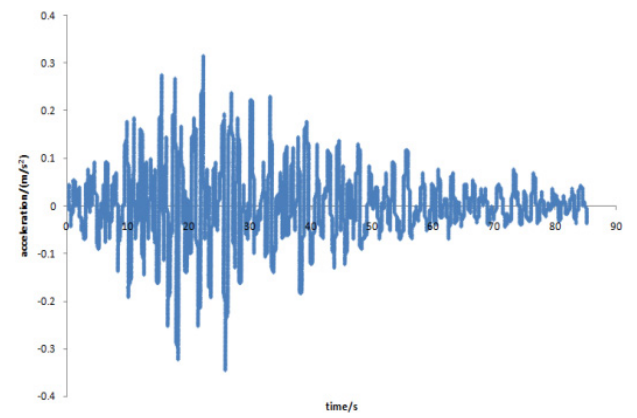

Fig. 26. Curve for acceleration time-history of spux seismic loading

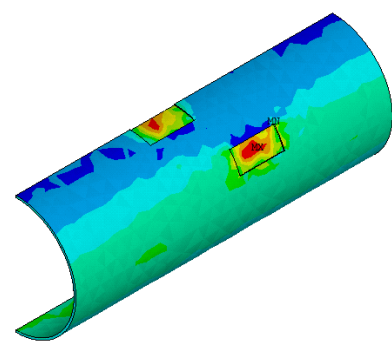

b) Taft seismic loading

a) EL-centro seismic loading

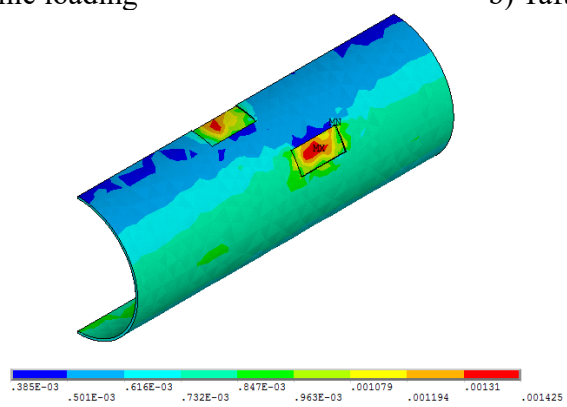

c) Spux seismic loading

Fig. 27. Distribution position for maximum strain of acceleration time-history with different types of seismic loading 


\subsection{Influence of seismic loading}

In the premise of other load boundary conditions and displacement boundary conditions are invariant, EL-centor seismic loading, Taft seismic loading and spux seismic loading are applied to the pipelines with double corrosion defects respectively. In order to make the calculation results comparable, the first thirty second acceleration of each seismic loading are applied to the mechanical model. The acceleration time history curves of Taft seismic loading and spux seismic loading are shown in Figs. 25-26 respectively. The maximum strain distribution of the corroded pipeline is shown in Fig. 27.

Fig. 27 shows that when the time of the seismic loading action is 30 seconds, the pipeline strain does not change with the change of different seismic loading. This is due to the short time and the great intensity of earthquake.

\section{Conclusions}

For corroded pipelines in cold regions, considering the nonlinear properties of the material of pipeline steel and the frost heave characteristic of soil, the three-dimensional thermal-fluid-solid coupling mechanics model is established, method by FEM (finite element method). The model is applied to do the dynamic response analysis for corroded pipelines under seismic loading, and the different influence factors on the mechanical properties of pipelines are then discussed.

The results show that for the different influence factors, the relative corrosion depth, the fluid pressure and the fluid temperature have obvious influence on the mechanical characteristics of the pipeline with double corrosion defects, the relative corrosion width comes second, and the relative corrosion length has less influence on it. The mechanical characteristics of pipeline do not change with different seismic loading. When the relative corrosion depth increases by 1 times, the strain increases by $69.4 \%$; when the fluid pressure increases by 1.5 times, the strain increases by about 1 times; when the fluid temperature increases by $50 \%$, the strain increases by $18.5 \%$.

The three-dimensional multi-field coupling mechanics model and the calculation method established in this paper provide an analytical method and theoretical basis for the evaluation of pipeline integrity in cold regions. In order to ensure that the buried pipelines in cold regions operate safely and steadily, the fluid pressure, fluid temperature and the relative corrosion depth should be the key factors monitored in the process of pipeline integrity management, and targeted measures of maintenance should be taken.

\section{Acknowledgements}

This work was partly supported by National Natural Science Foundation of China (No. 51674086).

\section{References}

[1] Fang J. P., Duan Q. Q. Failure analysis of oil and gas pipeline in low temperature permafrost area. Oil and Gas Transportation and Storage, Vol. 34, Issue 3, 2016, p. 7-10.

[2] Clark J., Phillips R. Centrifuge modeling of frost heave of arctic gas pipelines. The 8th International Conference on Permafrost, 2003.

[3] Palmer A. C., Williams P. J. Frost heave and pipeline upheaval buckling. Canadian Geotechnical Journal, Vol. 40, Issue 1, 2003, p. 1033-1038.

[4] Zhang K., Lian Z. H., Xia Y. B., et al. Analysis of thermal deformation of buried pipeline in permafrost zone. Petroleum Engineering Construction, Vol. 32, Issue 4, 2006, p. 4-6.

[5] Li S. L. Influence Analysis for Frozen Soil Expansion on Stress Change of Regulating Station Pipeline. Capital University of Economics and Business, Beijing, 2014.

[6] Tang M. C. Calculation of Thermal-Stress on Shallow-buried Oil pipeline in Cold Area. Tongji University, Shanghai, 2007. 
[7] Li K., Wang Z. F., Xiang W. D., et al. Mechanical analysis of frost heaving of pipeline in gas offtake station. Oil and Gas Storage and Transportation, Vol. 30, Issue 8, 2011, p. 652-656.

[8] Fokeeva M., Radina E. Influence of permafrost conditions on gas mains stability in cryolithozone. Journal of Glaciology and Geocryology, Vol. 26, 2004, p. 215-219.

[9] Li Y. H., Wu W., Hao J. Q., et al. Determination of the wall thickness for designing the steel pipe in frozen ground along the China-Russia crude oil pipeline route. Journal of Glaciology and Geocryology, Vol. 30, Issue 4, 2008, p. 605-610.

[10] Zhu Q. J., Chen Y. H., Liu T. Q., et al. Finite element analysis of fluid-structure interaction in buried liquid-conveying pipeline. Journal of Central South University of Technology, Vol. 15, Suppl. 1, 2008, p. 307-310.

[11] Shao G. B. Numerical analysis for oil pipeline subjected to earthquake liquefaction-induced lateral spreading. Advanced Materials Research, Vols. 243-249, 2011, p. 3804-3807.

[12] Hu Y. W. Study on the Effect of Site Subsidence on Buried Pipeline. Institute of Engineering Mechanics, China Earthquake Administration, Harbin, 2008.

[13] Fang J. P. Accident Analysis of domestic and international oil and gas pipelines. Oil and Chemical Equipment, Vol. 19, 2016, p. 90-93.

[14] Yu H. Forward and Reverse Transporting Optimization Technology Research of Su Cuo Oil Pipeline. Northeast Petroleum University, Daqing, 2016.

[15] Yang S. M., Tao W. Q. Heat Transfer. Higher Education Press, Beijing, 2006, p. $42-44$.

[16] Shuai J. Pipeline Mechanics. Science Press, Beijing, 2010, p. 198-199.

[17] Sun H. Study and Application on Coupled Fluid-Solid and Heat-Fluid-Solid Theories of Sand Control Technology in Weakly Consolidated Reservoirs. China University of Petroleum, Qingdao, 2008, p. 87-89.

[18] Zhao X., Ma Y. X., Wu Z. F., et al. Study on security of long-distance transport X52 pipeline in suspended state. Mechanical Science and Technology for Aerospace Engineering, Vol. 34, Issue 10, 2015, p. 1589-1593.

[19] China National Standardization Management Committee. GB150-2011, Pressure Vessel, 2012.

[20] Li N. S., Xie L. H., Chen X. H. Frozen heaving of frost soli bed of shallow buried oil pipeline in cold region. Structural Engineers, Vol. 24, Issue 1, 2008, p. 35-40.

[21] Li H. The Study on the Stability of the Embankment Upon the Slope under Earthquake Load in Permafrost Area. Beijing Jiaotong University, Beijing, 2010.

[22] Wang H. L., Chen Q. J. Comparison of wave- passage effect on large-span connective structures under different seismic waves. Journal of Jiamusi University (Natural Science Edition), Vol. 31, Issue 4, 2013, p. 510-515.

[23] Cao W. R., Qi L., Cao X. F. Numerical analysis of dynamic response of submarine pipeline under seismic loading. Proceedings of China Oil and Gas Forum - A Special Symposium on Oil and Gas Pipeline Technology, 2014, p. 659-663.

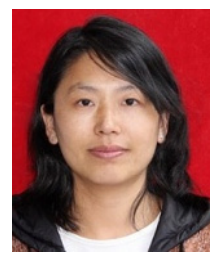

Qiao-zhen Li is a Ph.D. student of petroleum and natural gas engineering in the School of Petroleum Engineering, Northeast Petroleum University. Her current research interests include pipeline integrity management, equipment safety evaluation, finite element analysis and simulation technology.

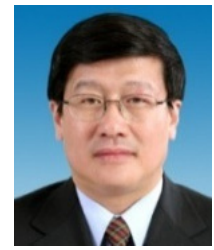

Yang Liu received Ph.D. degree in computational mechanics from Dalian University of Technology, Liaoning, China, in 1988. Now he is a Professor in School of Petroleum Engineering, Northeast Petroleum University. His current research interests include research on energy saving technology and safety evaluation technology of oil and gas storage and transportation engineering. 


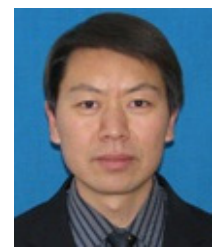

Li-xin Wei received Ph.D. degree in oil-gas field development engineering from Northeast Petroleum University, Daqing, China, in 2005. Now he is a Professor in School of Petroleum Engineering, Northeast Petroleum University. His current research interests include research on energy saving technology and safety evaluation technology of oil and gas storage and transportation engineering.

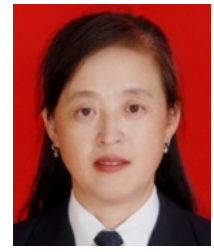

Min Luo received Ph.D. degree in chemical industry process machinery from Northeast Petroleum University, Daqing, China, in 2009. Now she is a Professor in College of Mechanical Science and Engineering, Northeast Petroleum University. Her current research interests include finite element analysis of petroleum and petrochemical equipment, mechanical analysis of rod string in oil well. 